\title{
Diagnosis and Surgical Treatment of Hepatic Hydatid Disease
}

\author{
AHMET BILGE* and ERDOĞAN M. SÖZÜER* \\ * Department of Surgery, Erciyes University, Medical School, Kayseri, Turkey
}

(Received 30 July 1990)

\begin{abstract}
In this report, 226 patients with hydatid disease admitted to the Surgical Department of Erciyes University (Kayseri) and Sişli Etfal Hospital (Istanbul) in Turkey between 1978 and 1990 were reviewed retrospectively. 102 patients $(45.1 \%)$ were male and $124(54.9 \%)$ female. The most frequent symptom was right upper abdominal pain $(66 \%)$. The most frequent signs were hepatomegaly $(43.8 \%)$ and palpable mass $(39 \%) .167$ patients $(73.9 \%)$ were examined with ultrasonography which has a diagnostic value of $94 \%$. Preoperative complications were infection of cyst $(7 \%)$, intrabiliary rupture $(3.5 \%)$ and anaphylactic shock $(0.4 \%)$. Patients were operated on by various techniques; omentoplasty (101), external drainage of residual cavity (64), marsupialization (25), capitonnage (15), introflexion (10), pericystectomy (6), and hepatic resection (5). Main postoperative complications were wound infection (12\%) and biliary fistula $(2.6 \%)$. Total mortality rate was $1.8 \%$ in this series.
\end{abstract}

KEY WORDS: Hepatic hydatid cyst disease omentoplasty introflexion

\section{INTRODUCTION}

Hydatid disease of the liver remains an important health problem worldwide, including Turkey. Especially it is endemic in many sheep grazing areas. As a result of easy travel and migration, the disease is now being encountered in immigrant adults in many parts of the world ${ }^{1,2}$. Hydatid cysts of the human liver occur when man becomes an accidental intermediate host for the larval form of Echinococcus granulosus, which lives as an adult worm in the canine intestine. The liver is the most common site infected in the adult. About one-third of patients with liver hydatid cysts have other sites involved, including peritoneum, lungs, spleen, brain, bone and thyroid. In this study, the various surgical techniques were compared with regard to post-operative complications, hospital stay, return to

Correspondance to: Ahmet Bilge, Department of Surgery, Medical School, Erciyes University, Kayseri, Turkey. activity and convalescence time. Herein, we discuss our experience over a 12 year period.

\section{PATIENTS AND FINDINGS}

226 patients with hepatic hydatid disease underwent surgical treatment at the Surgical Department of Erciyes University and Şişli Etfal Hospital (Istanbul). Patients' ages ranged from 15 to 75 (median 49) years. 102 patients $(45.1 \%)$ were male and $124(54.9 \%)$ female.

\section{Symptom and Signs}

Symptoms arise from local pressure, leakage, infection and rupture into the biliary tree. Right upper abdominal pain, hepatic enlargement, or a palpable mass were the most common signs of the disease. Pain may result from stretching of the liver capsule or leakage of contents. Leakage may also produce urticeria or 
anaphylaxis when cyst fluid is absorbed into the blood stream. The duration of symptom and signs ranged from 2 weeks to 8 years. The most common clinical findings are shown in Table 1.

\section{Diagnosis of the Disease}

The diagnosis of hydatid disease of the liver is usually made easily when a liver cyst is found in a patient from an endemic area. Calcification of the cyst wall is commonly seen on plain X-ray films. Ultrasound shows the characteristic picture of a cyst containing multiple daughter cysts. In 28 patients who had radionuclide scanning of the liver, lesions were confirmed in all of them. Ultrasonographic examination was used in 167 patients and demonstrated hepatic cysts with $94 \%$ accuracy (Table 2). Ultrasound was also accurate in locating the site, size and number of intrahepatic cysts, together with contained daughter cysts. Serological studies, the Casoni's skin test and Weinberg's test yielded poor results in patients tested. Preoperative complications found in 25 patients were infection of cyst, intrabiliary rupture and anaphylactic shock (Table 3).

\section{Surgical Techniques}

Cysts were mainly found in the right lobe (76\%). Only $24 \%$ of cysts were localised in the left lobe. $147(65 \%)$

Table 1 The clinical features of hepatic hydatid disease in 226 patients

\begin{tabular}{lcl}
\hline Clinical findings & $n$ & $\%$ \\
\hline Right upper abdominal pain & 149 & 66 \\
Hepatic enlargement & 99 & 43.8 \\
Palpable mass & 88 & 39 \\
Anorexia, weight loss & 57 & 25 \\
Nausea and vomiting & 48 & 21 \\
Fever and chills & 27 & 12 \\
Dispnea & 23 & 10 \\
Jaundice & 7 & 3.1 \\
Persistent cough & 5 & 2.2 \\
Urticeria and anaphylaxis & 1 & 0.4 \\
\hline
\end{tabular}

Table 2 The accuracy of diagnostic procedures

\begin{tabular}{lrcc}
\hline Diagnostic procedure & $n$ & Accuracy & $\%$ \\
\hline Ultrasound & 167 & 157 & 94 \\
Plain X-ray & 226 & 84 & 37.1 \\
Casoni's skin test & 62 & 42 & 67.7 \\
Weinberg test & 56 & 31 & 55.4 \\
Radionuclide scan & 28 & 28 & 100 \\
\hline
\end{tabular}

Table 3 Preoperative complications of the liver cysts

\begin{tabular}{lrc}
\hline Complication & $n$ & $\%$ \\
\hline Infection of cyst & 16 & 7 \\
Rupture into biliary tract & 8 & 3.5 \\
Intraperitoneal rupture & 1 & 0.4 \\
\hline Total & 25 & 11 \\
\hline
\end{tabular}

patients had a single cyst, $38(16.8 \%)$ had $2,27(12 \%)$ had 3 cysts and $14(6.2 \%)$ patients had 4 or more cysts. In order to compare the results, in this study the patients are best analysed in two groups: uncomplicated cysts 201 patients ( $89 \%$ ) and complicated cysts 25 patients $(11 \%)$.

Uncomplicated cysts

In this group, the residual cavity was filled with pedicled omentum in 87 and with liver tissue in 25 patients. The cavity was simply drained in 79 patients (Table 4). In this group 33 patients developed various complications showed in Table 5.

Complicated cysts

In this group biliary drainage was added to omentoplasty in 8 patients with intrabiliary rupture. In 16 patients with an infected cyst this was drained like a liver abscess (Table 6). The rate of complications was found to be very high (Table 7).

Postoperative morbidity such as; mean postoperative hospital stay, return to daily activity and

Table 4 Operative techniques in uncomplicated cysts $(n=201)$

\begin{tabular}{ll}
\hline Surgical technique & $n$ \\
\hline Omentoplasty & 87 \\
External drainage & 64 \\
Marsupialization & 15 \\
Capitonnage & 15 \\
Introflexion & 10 \\
Pericystectomy & 6 \\
Hepatic resection & 4 \\
\hline
\end{tabular}

Table 5 Postoperative complications in 201 patients with uncomplicated cyst

\begin{tabular}{lcc}
\hline Complication & $n$ & $\%$ \\
\hline Wound infection & 24 & 12 \\
Infection of residual cavity & 3 & 1.5 \\
Biliary fistula & 3 & 1.5 \\
Pulmonary infection & 3 & 1.5 \\
\hline Total & 33 & 16.4 \\
\hline
\end{tabular}


Table 6 Surgical techniques in complicated cysts $(n=25)$

\begin{tabular}{lc}
\hline Complication and surgical procedures & $n$ \\
\hline Intrabiliary rupture (8 patients) & 5 \\
Omentoplasty + T tube & 2 \\
Omentoplasty + Cholecystectomy + Cholodochoduodenostomy & 1 \\
Omentoplasty + Cholecystectomy + Sphincteroplasty & 10 \\
Infection of cyst (16 patients) & 6 \\
Marsupialization & 1 \\
Omentoplasty & 1 \\
Intraperitoneal rupture (1 patient) & \\
Hepatic resection & \\
\hline
\end{tabular}

Table 7 Postoperative complications in 25 patients with complicated cysts

\begin{tabular}{lcc}
\hline Complication & $n$ & $\%$ \\
\hline Wound infection & 3 & 12 \\
Biliary fistula & 3 & 12 \\
Infection of residual cavity & 2 & 8 \\
Pulmonary infection & 2 & 8 \\
Intraabdominal abscess & 1 & 4 \\
\hline Total & 11 & 44 \\
\hline
\end{tabular}

period of drainage were found to be significantly longer in the complicated group than the uncomplicated group (Tables 8 and 9).

Four patients died due to myocardial infarction (2) and renal failure (2). The mortality rate was $1.8 \%$ in

Table 8 Mean postoperative hospital stay and return to daily activity

\begin{tabular}{lll}
\hline Group & $\begin{array}{l}\text { Postoperative stay } \\
\text { (days) }\end{array}$ & $\begin{array}{l}\text { Return to activity } \\
\text { (days) }\end{array}$ \\
\hline Uncomplicated $(n$ 201) & 12 & 61 \\
Complicated $(n$ 25) & 23 & 94 \\
& $p<0.001$ & $p<0.001$ \\
\hline
\end{tabular}

Table 9 Period of drainage and hospital stay related to surgical procedures

\begin{tabular}{lll}
\hline Surgical procedure & $\begin{array}{l}\text { Hospital stay } \\
\text { (days) }\end{array}$ & $\begin{array}{l}\text { Period of drainage } \\
\text { (days) }\end{array}$ \\
\hline Omentoplasty & 11.5 & 7.8 \\
External drainage & 12.5 & 9.2 \\
Marsupialization & 29.5 & 47 \\
Capitonnage & 13.6 & 11 \\
Introflexion & 10.5 & 7 \\
Pericystectomy & 14 & 13 \\
Hepatic resection & 15 & 13 \\
\hline
\end{tabular}

this series. The follow-up period ranged from 3 months to 5 years (average 2.8 years). No patient underwent late surgery for a reason related to hydatid disease.

\section{DISCUSSION}

In endemic areas the diagnosis of hepatic hydatid cyst is no longer a difficult problem. Especially after introducing organ imaging techniques; ultrasonography and computerised tomography, exact confirmation of cysts has become a much easier task ${ }^{1,3}$. In this study the imaging procedures ultrasonography and radionuclide scanning yielded very high percentage accuracy, $94 \%$ and $100 \%$ respectively.

The treatment of hydatid cyst is surgery. The principles of surgical management for hepatic echinococcosis, include 1) neutralisation of the parasite, 2) evacuation of the cyst and removal of the germinal lining, and 3) management of the residual cavity. Complete surgical removal which is the ideal treatment of the disease, can be accomplished by removal of all germinal lining, daughter cysts, fluid and scolices leaving the pericyst; or by resection of the intact cyst including pericyst ${ }^{4}$. At first, whichever method is used, cyst fluid should be neutralised to prevent accidental spillage of scolices or germinal lining into the operative field. Numerous solutions such as, hypertonic saline solution, $2 \%$ formalin, $0.5 \%$ silver nitrate, $10 \%$ aqueous povidone iodine and formalin have been used as a scolicidal agent. There is debate not only as to the most effective scolicide but also about the necessity of scolicidal injection before cyst evacuation ${ }^{5,6}$. Instead of using a scolicidal agent, a cryogenic cone has been developed to obtain entry to and evacuation of the cyst without fear of spillage into the peritoneal cavity ${ }^{6}$. We have no experience of this method or of the suction cone devised by Aarons and Kune ${ }^{7}$. The use of scolicidal agents has a long tradition but there is little 
evidence to justify their use and they are probably of negligible value in multivesicular cysts ${ }^{5}$. Perhaps the most important aspect of the manoeuvre is partial decompression of the cyst contents which are under tension. Recently $0.5 \%$ silver nitrate has become the solution of choice for many surgeons, including us. The solution of formalin causes sclerosing cholangitis and has never been used in this series.

Because of the fear of spillage of cyst elements during surgery, medical treatment has been used for hepatic hydatid cysts preoperatively and /or postoperatively. Lastly some reports have advocated the successful management of hydatid disease using benzimidazole compounds (mebendazole, albendazole) in small numbers of patients ${ }^{8-13}$. Because the general results are not reliable, medical treatment is not curative at present. Thus, these drugs should be reserved for patients who will not tolerate operation and, perhaps, for those with the more virulent form of alveolar hydatid disease of the liver caused by Echinococcus multilocularis.

The most difficult problem to be solved in the treatment of hydatid cyst of the liver is the residual cavity. After evacuation of cyst fluid all the simple communications between biliary tree and cyst cavity are open. This is the cause of biliary leakage postoperatively. A wide variety of techniques have been carried out to deal with the residual cavity after evacuation to prevent biliary leakage, biliary fistula and abscess. For techniques include: hepatic resection ${ }^{2,14}$, pericystectomy $^{15,16}$, omentoplasty ${ }^{1,17,18}$, capitonnage ${ }^{19}$, cystojejunostomy ${ }^{20}$, marsupialization, external drainage ${ }^{21}$, introflexion ${ }^{22}$, saucerisation and finally primary closure after saline instillation ${ }^{23}$. In selecting a particular surgical technique, the surgeon should be guided by the size and location of the cyst and the existence of complications. Whenever possible, we managed the residual cyst cavity by omentoplasty. It has been shown that this technique reduces hospital stay and lowers the incidence of biliary fistula compared with marsupialization or tube drainage ${ }^{17}$. Our findings in 87 patients treated with omentoplasty confirm these satisfactory results. The omentum may obliterate the residual cavity and prevent secondary infection. This seems to be an advantage of omentoplasty, as infection is quite uncommon. However, in some patients, the omentum may not be available because of previous surgery or the technique cannot be performed because of the very high and far location of the cyst. Furthermore omentoplasty itself can cause formation of adhesions which, consequently, makes future operations upon the liver more difficult.
Introflexion is also an alternative safe method for the treatment of the remaining cavity. It may be easily applied in most of the patients with a cyst located peripherally. This technique not only prevents dead space and its possible potential complications, but also covers the inner surface of the cystic cavity by several layers of peritoneum, which has been demonstrated to have a high resorptive capacity ${ }^{22,24}$. The omentoplasty resembles introflexion in that it enables the omentum to fill the cavity with its absorptive capacity; however, introflexion is almost always applicable, whereas omento-plasty is either difficult or impossible, at least in some instances ${ }^{10}$. These two method can be used alternatively.

In the capitonnage method, the cystic walls are approximated by sutures to obliterate the cavity. Sometimes adjacent intrahepatic vessels may be injured; moreover, approximation may be very difficult or impossible in large cavities.

Marsupialization of the residual cavity has not been performed in our clinic for ten years, because its results have been unsatisfactory.

Because of the risk of spillage of infective material into the peritoneal cavity leading to recurrent disease, some authors have favoured resection ${ }^{2,14}$, but this approach carries a significant operative risk and is not applicable in many cases ${ }^{4}$. Total cystectomy may be preferred for cysts located peripherally. Hepatic lobectomy and pericystectomy are, in our opinion, too radical and extensive procedures for a benign lesion.

Although intrabiliary rupture is the commonest complication of hepatic hydatid cysts ${ }^{5,25}$, in this series it is infection. The pressure inside the cysts is always higher than the pressure in the biliary tract and after rupture the cyst elements pass into the biliary ducts. The cyst material does not die in the biliary channels and may cause obstruction and cholangitis at any stage of their life cycle ${ }^{3,26}$. Eight patients in this series (3.5 per cent) had cholangitis due to intrabiliary rupture of an hydatid cyst. The principles of operative management in these cases were to treat the mother cyst and to clear the biliary tree of any hydatid material. In this case operative confirmation of intrabiliary rupture is very important. There are two strategies to the operation. The first step is the surgical treatment of the cyst. The second is the exploration and drainage of the common bile duct. From the point of view of the intrabiliary rupture any technique can be used for management of the cyst cavity but the removal of all the cystic elements from biliary ducts is a very important task ${ }^{3,26}$. Drainage of the dilated common bile duct may be essential to avoid death from suppurative cholangitis or septic 
shock $3,26,27,28,29$. A drainage procedure, $T$ tube $^{29,30,31}$, sphincterotomy ${ }^{32}$, choledocho-duodenostomy ${ }^{3,26}$ or cystojejunostomy ${ }^{21,31}$ should be added if there is any doubt about free biliary drainage.

In many large series of echinococcal liver cysts, operative mortality has ranged from 2 to 4 per cent, but has recently been reported to be as high as 6.3 per cent ${ }^{14,17}$. In our series, the mortality rate was $1.8 \%$.

From the results of this study, it is clear that a closed cavity with a narrow stoma should not be left after evacuation of an hydatid cyst in the liver. The cavity should be obliterated if it is possible. Omentoplasty and introflexion could be used no needed. Nevertheless, it is clear that complicated cysts cause significantly more morbidity than uncomplicated cysts. Therefore early diagnosis and early surgical treatment are essential for good results.

\section{REFERENCES}

1. Kune, G. A. (1985) Hydatid disease. In Maingot's Abdominal Operations, edited by Schwartz, S. I., Ellis, H., 8th edn. pp. 16051624, Connecticut: Appleton-Century-Crofts.

2. Pissiotis, C. A., Wander, J. U., Condon, R. E. (1972) Surgical treatment of hydatid disease. Prevention of complications and recurrence. Arch. Surg., 104, 454-459.

3. Bilge, A., Bengisu, N., Toyganözü, Y., Alper, A. (1988) Evaluation and treatment of patients with obstructive jaundice. Japanese Journal of Medical Imaging, 7(1), 58-63.

4. Langer, B. (1987) Surgical treatment of hydatid disease of the liver. Br. J. Surg., 74, 237-238.

5. Dawson, J. L., Stamatakis, J. D., Stringer, M. D., Williams, R. (1988) Surgical treatment of hepatic hydatid disease. Br. J. Surg., 75, 946-950.

6. Saidi, F. (1977) A new approach to the surgical treatment of hydatid cysts. Ann. R. Coll. Surg. Engl., 59, 115-128.

7. Aarons, B. J., Kune, G. A. (1983) A suction cone to prevent spillage during hydatid surgery. Aus. Nz. Surg., 53, 471-474.

8. Muller, E., Ekovbiantz, A., Ammann, R. W. (1982) Treatment of human echinococcosis with mebendazole: preliminary observations in 28 patients. Hepatogastroenterology, 29, 236-239.

9. Musio, F., Linos, D. (1989) Echinococcal disease in an extended family and review of the literature. Arch. Surg., 124, 741-744.

10. Pitt, H. A., Korzelius, J., Tompkins, R. (1986) Management of hepatic echinococcosis in Southern California. Am. J. Surg., 152, $110-115$.

11. Ronconi, P., Boraone, A., Alquati, P. (1982) Preoperative treatment of hydatid cysts with mebendazole. Int. Surg., 67, 405-406.
12. Saimod, A. G., Meulemans, A., Cremieux, A. C. (1983) Albendazole as a potential treatment for human hydatidosis. Lancet, $\mathbf{2}$, 652-656.

13. Smego, D. R., Smego, R. A. Jr. (1986) Hydatid cyst, preoperative sterilisation with mebendazole. South Med. J., 79, 900-901.

14. Belli, L., Favero, E., Marni, A., Romani, F. (1983) Resection versus pericystectomy in the treatment of hydatidosis of the liver. Am. J. Surg., 145, 239-242.

15. Placer-Galan, C., Martin, R., Jimenez, R., Soleto, E. (1987) A simplified technique for surgical management of echinococcal cyst. Surg. Gynecol Obstet, 165, 269-270.

16. Belli, L., Romani, F., Puttini, M. (1987) Easier and safer cystopericystectomy using the pringle manoeuvre. Surg. Gynecol Obstet, 164, 75-76.

17. Papadimitriou, J., Mandrekas, A. (1970) The surgical treatment of hydatid disease of the liver. Br. J. Surg., 57, 431-433.

18. Little, J. M., Deane, S. A. (1986) Hydatid disease. In Liver Surgery, edited by Bengmark, S., Blumgart, L. H., pp. 118-129, Edinburgh: Churchill Livingstone.

19. Akinoğlu, A., Bilgin, I., Erkoçak, E. U. (1985) Surgical management of hydatid disease of the liver. Can. J. Surg., 28, 171-174.

20. Sekar, N., Mahajan, K. K., Kaushik, S. P., Katariya, R. N. (1982) Pericystojejunostomy in the treatment of hydatid cysts of the liver. Aus. NZ J. Surg., 52, 76-78.

21. Barros, J. L. (1978) Hydatid disease of the liver. Am. J. Surg., 135, $597-600$.

22. Arioğul, O., Emre, A., Alper, A., Uras, A. (1989) Introflexion as a method of surgical treatment for hydatid disease. Surg. Gynecol Obstet, 169, 356-358.

23. Ekrami, Y. (1976) Surgical treatment of hydatid disease of the liver. Arch. Surg., 111, 1350-1352.

24. Condon, R. E., Malangoni, M. A. (1984) Peritonitis and intraabdominal abscesses. In Principles of Surgery, edited by Schwartz, S. I., Shires, G. T., Spencer, F. C., Storer, E. H., pp. 1391-1392, New York: McGraw-Hill Book Co.

25. Androulakis, G. A. (1986) Surgical management of complicated hydatid cysts of the liver. Eur. Surg. Res., 18, 145-150.

26. Alper, A., Arloğul, O., Emre, A., Ökten, A. (1987) Choledochoduodenostomy for intrabiliary rupture of hydatid cysts of liver. Br. J. Surg., 74, 243-245.

27. Cottone, M., Amuso, M., Cotton, P. B. (1978) Endoscopic retrograde cholangiography in hepatic hydatid disease. Br. J. Surg., 65, 107-108.

28. Ovnat, A., Peiser, J., Avinoah, E., Barki, Y., Charuzi, I. (1984) Acute cholangitis caused ruptured hydatid cyst. Surgery, 95, 497-500.

29. Sayek, I., Yalin, R., Sanaç,Y. (1980) Surgical treatment of hydatid disease of the liver. Arch. Surg., 115, 847-850.

30. Dadoukis, J., Gamvros, O., Aletras, H. (1984) Intrabiliary rupture of the hydatid cyst of the liver. World J. Surg., 8, 786-790.

31. Lygidakis, N. J. (1983) Diagnosis and treatment of intrabiliary rupture of hydatid cyst of the liver. Arch. Surg., 118, 1186-1189.

32. Moveno, V. F., Lopez, E. V. (1985) Acute cholangitis caused by ruptured hydatid cyst (letter). Surgery, 97, 249-250. 


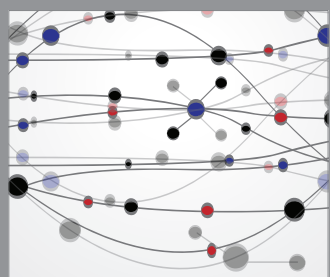

The Scientific World Journal
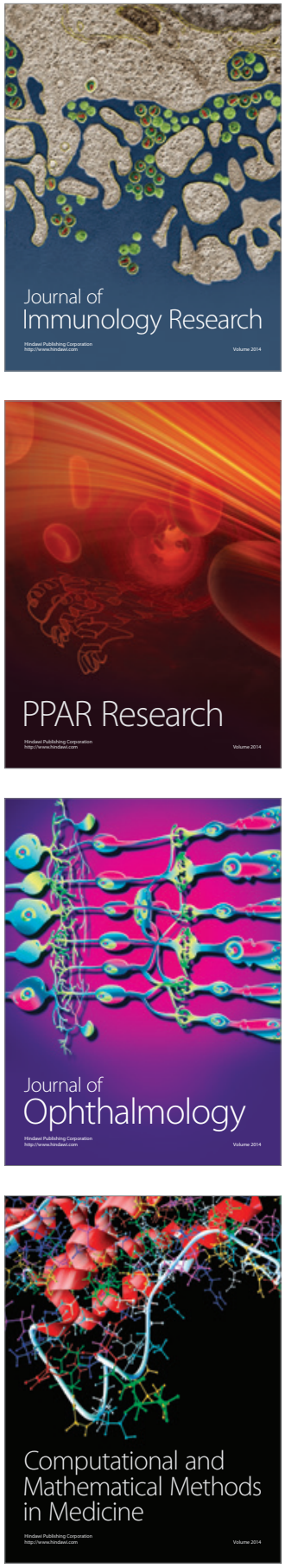

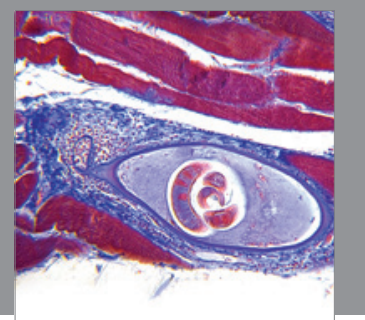

Gastroenterology

Research and Practice
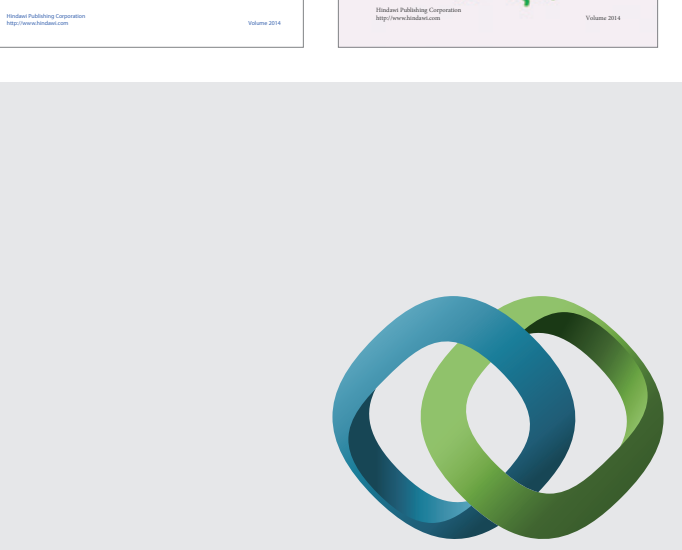

\section{Hindawi}

Submit your manuscripts at

http://www.hindawi.com
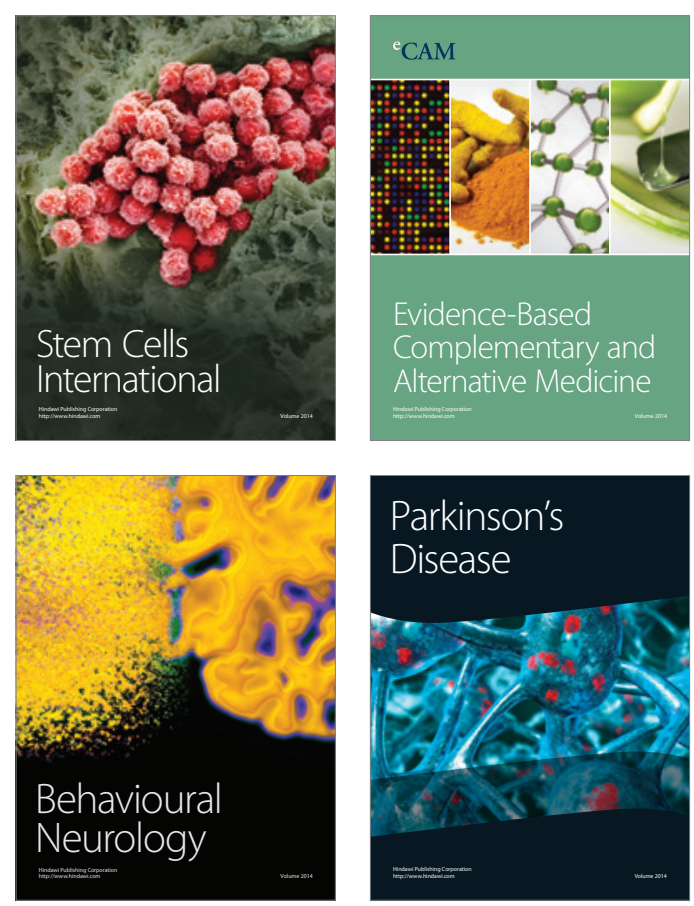

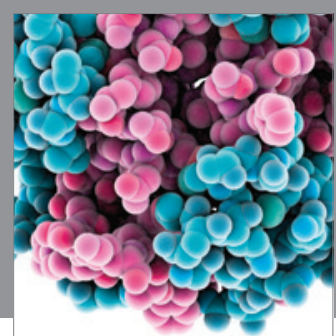

Journal of
Diabetes Research

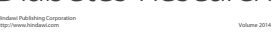

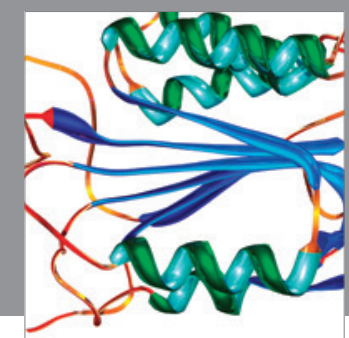

Disease Markers
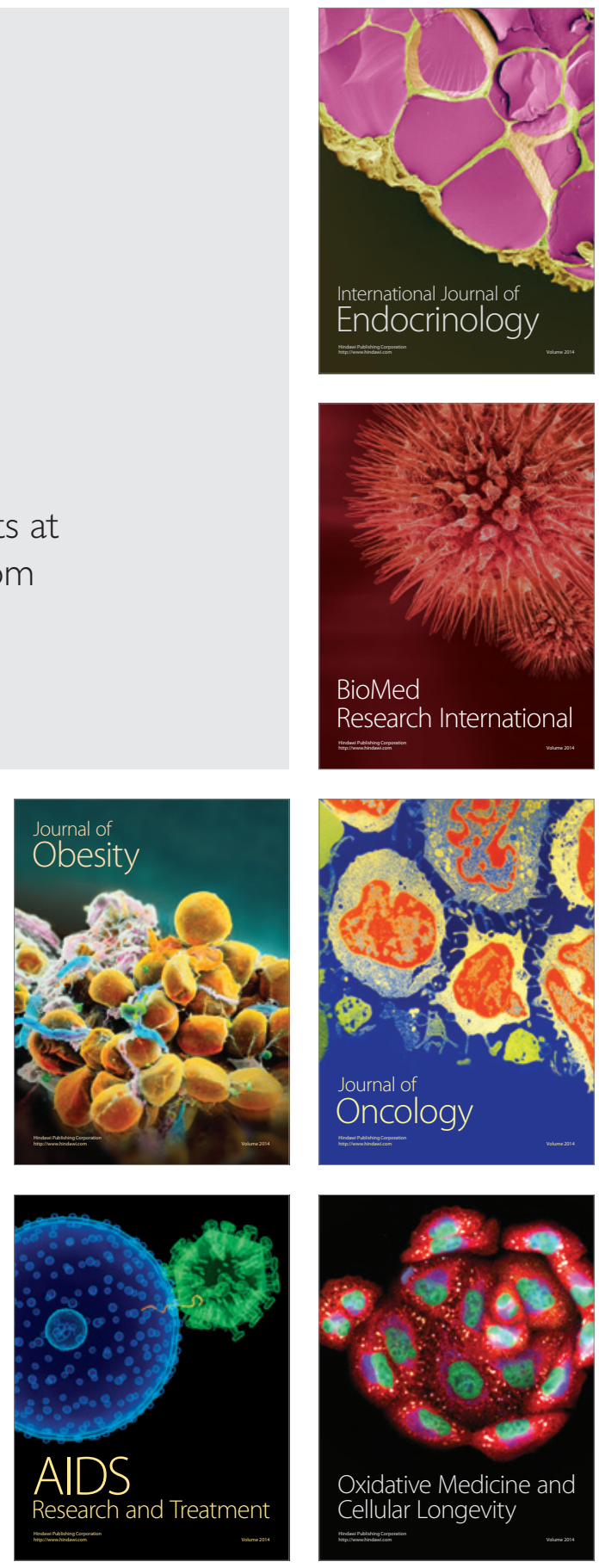